\title{
Correction to: Addressing challenges in scaling up TB and HIV treatment integration in rural primary healthcare clinics in South Africa (SUTHI): a cluster randomized controlled trial protocol
}

\author{
Kogieleum Naidoo ${ }^{1,2^{*}}$ (D), Santhanalakshmi Gengiah', Nonhlanhla Yende-Zuma', Nesri Padayatchi ${ }^{1,2}$, Pierre Barker ${ }^{3,4}$,
} Andrew Nunn ${ }^{5}$, Priashni Subrayen ${ }^{6}$ and Salim S. Abdool Karim ${ }^{1,2,7}$

\section{Correction to: Implement Sci}

https://doi.org/10.1186/s13012-017-0661-1

Following publication of the original article [1], the authors reported an error in the wording of the study hypothesis. The error occurs in the Aims and Objectives sub-section of the Methods section and is highlighted in bold below.

The original article reads:

The hypothesis is that survival rates will be lower in TB, HIV, and TB-HIV co-infected patients accessing health care at clinics implementing the study intervention to deliver integrated TB-HIV care, compared to survival in patients accessing health care at clinics that provide only the standard of care for people with TB and or HIV.

The sentence should read:

The hypothesis is that survival rates will be higher in TB, HIV, and TB-HIV co-infected patients accessing health care at clinics implementing the study intervention to deliver integrated TB-HIV care, compared to survival in patients accessing health care at clinics that provide only the standard of care for people with TB and or HIV.

\begin{abstract}
Author details
${ }^{1}$ Centre for the AIDS Programme of Research in South Africa (CAPRISA), Nelson R Mandela School of Medicine, Private Bag X7, Congella, Durban 4013, South Africa. ${ }^{2}$ CAPRISA-MRC TB-HIV Pathogenesis and Treatment Research Unit, Durban, South Africa. ${ }^{3}$ Institute for Healthcare Improvement, Cambridge, MA, USA. ${ }^{4}$ Gillings School of Global Public Health, UNC Chapel Hill, Chapel Hill, USA. ${ }^{5}$ Medical Research Council Clinical Trials Unit at University College London, London, UK. ${ }^{6}$ BroadReach, Durban, South Africa. ${ }^{7}$ Department of Epidemiology, Mailman School of Public Health, Columbia University, New York, NY, USA
\end{abstract}

Received: 6 June 2019 Accepted: 6 June 2019

Published online: 13 June 2019

\section{Reference}

1. Naidoo $\mathrm{K}$, et al. Addressing challenges in scaling up TB and HIV treatment integration in rural primary healthcare clinics in South Africa (SUTHI): a cluster randomized controlled trial protocol. Implement Sci. 2017;12:129. https://doi.org/10.1186/s13012-017-0661-1.

\footnotetext{
* Correspondence: Kogie.Naidoo@caprisa.org

${ }^{1}$ Centre for the AIDS Programme of Research in South Africa (CAPRISA),

Nelson R Mandela School of Medicine, Private Bag X7, Congella, Durban

4013, South Africa

${ }^{2}$ CAPRISA-MRC TB-HIV Pathogenesis and Treatment Research Unit, Durban,

South Africa

Full list of author information is available at the end of the article
}

(c) The Author(s). 2019 Open Access This article is distributed under the terms of the Creative Commons Attribution 4.0 International License (http://creativecommons.org/licenses/by/4.0/), which permits unrestricted use, distribution, and reproduction in any medium, provided you give appropriate credit to the original author(s) and the source, provide a link to the Creative Commons license, and indicate if changes were made. The Creative Commons Public Domain Dedication waiver (http://creativecommons.org/publicdomain/zero/1.0/) applies to the data made available in this article, unless otherwise stated. 